\title{
Knowledge, Attitudes, and Practice of Cervical Cancer Prevention among Student Health Professionals in Nigeria
}

\author{
Anene-Okeke Chigozie Gloria ${ }^{1}$, Aluh Deborah Oyine ${ }^{2}$, Okorie Uzoamaka \\ Henrietta $^{3}$
}

${ }^{1}$ Department of Clinical Pharmacy and Pharmacy Management, University of Nigeria, Nsukka, Nigeria. ${ }^{2}$ Department of Clinical Pharmacy and Pharmacy Management, University of Nigeria, Nsukka, Nigeria. ${ }^{3}$ Department of Clinical Pharmacy and Pharmacy Management, University of Nigeria, Nsukka, Nigeria

\begin{abstract}
Background: Cervical cancer is the second most commonly diagnosed gynecological cancer affecting women worldwide. It is a preventable disease but still remains a leading cause of cancer deaths in developing countries like Nigeria despite the availability of preventive strategies. Undergraduate pharmacy and medical students are future health care providers who can help raise awareness and improve the knowledge of the public towards cervical cancer, it's screening, prevention and treatment. The study sought to assess the knowledge, attitudes and practice of cervical cancer screening and prevention. Materials and methods: This is a cross-sectional survey using a questionnaire conducted in the University of Nigeria and Nnamdi Azikiwe University both in South-eastern Nigeria. Participants were conveniently sampled and the self-administered questionnaire was given to 335 consenting female pharmacy and medicine undergraduate students. Results: 335 out of the 350 undergraduate students approached responded (95.7\% response rate). The result of the study shows that the students generally had a good level of awareness of cervical cancer. The students surveyed had a mean knowledge score of $75.9062 \pm 20.265$. More than a third $(36.1 \%, \mathrm{n}=214)$ of the students had a negative attitude towards cervical cancer. Only about one in eight students reported to having had a pap smear $(12.54 \%, \mathrm{n}=42)$. Conclusion: The students generally had a good awareness and knowledge of cervical cancer which was not translated into practice. There is a need to include public health principles into the curriculum of Pharmacy and Medical schools in Nigeria since they are future health advisors.
\end{abstract}

Keywords: Cervical cancer- knowledge- attitude- awareness- HPV Vaccine- Medical students- Pharmacy students

Asian Pac J Cancer Care, 4 (4), 125-130

\section{Introduction}

Cervical cancer is the second most commonly diagnosed gynecological cancer affecting women worldwide [1]. It is a preventable disease but still remains a leading cause of cancer deaths in developing countries like Nigeria despite the availability of preventive and curative protocols. Nigeria is the most populous country in Africa with an estimated population above 170 million in 2014 and with an estimated total population of women between $15-49$ years of age are about 40.43 million who are at risk of developing cervical cancer [2]. In Nigeria, the National Cancer Control Program was developed in 2008 with the view of reducing the morbidity and mortality associated with cancer and its socioeconomic impacts. The Federal
Submission Date: 04/14/2019 Acceptance Date: 07/11/2019

Ministry of Health (FMOH) established a cervical cancer control plan for screening and early detection of cervical cancer and human papillomavirus (HPV) vaccination for primary prevention in girls of 9-15 years [3]. The level of implementation of this plan is still debatable in Nigeria.

Several risk factors have been linked to cervical cancer, among these factors include early marriage or early age of first sexual intercourse (coitarche), multiple male sexual partners, long term use of oral contraceptive pills [4-6]. These sexual risk factors favor the sexual transmission of a carcinogen Human Papilloma Virus (HPV), which is associated with nearly all cervical cancer [7]. More than 99\% of Cervical cancer is associated with High-Risk Human Papilloma Virus (HR-HPV) and types 16 and 18 accounts for $70 \%$ of cases globally [4-8]. Vaccines

Corresponding Author:

Dr. Aluh Deborah Oyine

Department of Clinical Pharmacy and Pharmacy Management. University of Nigeria Nsukka.

Email: deborah.aluh@unn.edu.ng, aluhdeborah@yahoo.com 
designed to prevent cervical cancer occurrence and other diseases caused by infection of HPVs was approved in the U.S. in June 2006. It is the first and only vaccine to prevent cervical cancer, vulvar and vaginal pre-cancers caused by HPV types 16 and 18 and genital warts caused by HPV types 6 and 11. Primary prevention of cervical cancer can be achieved by immunization of young girls between the ages of 9-16 before sexual intercourse and cervical cancer screening for early detection and cure of cervical cancer as the secondary prevention, yet with all the advancements, the incidence of cervical cancer among women in Nigeria is increasing progressively. There are different screening programs that can be used to detect the precancerous changes so as to prevent the development of the diseases and curb its serious consequences. Some of these programs include; visual methods such as Pap smear or visual inspection with acetic acid (VIA), visual inspection with Lugol's iodine (VLI), HPV-DNA based screening among others. The screening programs are expected to be performed by qualified health professionals.

Female Health workers are expected to have a better understanding of the benefits of cervical screening than women in other spheres of life. Thus they should be effective agents in creating and disseminating information about the importance of the screening programs for the sexually active, post-menopausal women as well as immunization for the girl child between the ages of 9- 16 years. Thus their attitude and practice towards screening for cervical cancer have far-reaching implications to its acceptance consequently contributing to the reduction in death of women from cervical cancer. Undergraduate pharmacy and medical students are future health care providers who can help raise awareness and improve the knowledge of the public towards cervical cancer, it's screening, prevention, and treatment. Thus there is need to determine the knowledge, attitude, and practice of cervical cancer screening among pharmacy and medicine students in the University of Nigeria Nsukka and Nnamdi Azikiwe University Awka because these students are still undergoing training in the tertiary institution hence ensuring that they are well informed before becoming licensed health care providers.

\section{Materials and Methods}

\section{Study Design}

This is a cross-sectional survey using a questionnaire conducted to assess the knowledge, awareness, and practice of cervical cancer screening among female pharmacy and medical undergraduate students in Nigeria.

\section{Study Setting}

The research was carried out in two schools: Nnamdi Azikiwe University and the University of Nigeria. The University of Nigeria is located in Enugu state, Nigeria while Nnamdi Azikiwe University is located in Anambra state, Nigeria. Both Schools are premiere federal universities which enroll students from diverse backgrounds and ethnicities.

\section{Study Population}

The study population included female undergraduate students in 400 and 500 level of faculty of pharmaceutical sciences and 500 and 600 level of faculty of medicine in the University of Nigeria and Nnamdi Azikiwe University who were willing to participate in the study. The levels were chosen because they are the clinical classes and are expected to be more advanced in knowledge.

\section{The instrument for Data Collection}

A structured validated and modified questionnaire by Adibe \& Aluh was adopted for the study [9]. The questionnaire includes information on socio-demographic variables (Age, entry level, marital status, faculty, level). It comprises of four parts. The first part contains questions on awareness of cervical cancer and its prevention, the second part assesses the level of knowledge of cervical cancer, part three determines the attitude of students towards cervical cancer prevention and screening and the fourth part contains questions on behavioral risk factors for cervical cancer.

\section{Data Collection}

The self-administered questionnaire was given to 335 consenting female pharmacy and medicine undergraduate students. The students were asked to fill the questionnaire immediately when given and it was retrieved immediately after completion to avoid sourcing information online, misplacing it or discarding it.

\section{Data Analysis}

Data collected were coded and entered into Microsoft Excel and then exported to SPSS (Statistical Package for Social Sciences version 20. Descriptive data such as frequencies, percentages and means and standard deviation were used for measurement. Inferential statistics such as Chi-square, student T-test, and correlation analysis was conducted as appropriate. All statistical significance value was set at $\mathrm{P}<0.05$.

\section{Ethical Clearance}

Ethical clearance was obtained from the Research and Ethics Committee of the University of Nigeria teaching hospital Enugu State. Informed consent was obtained from all participants, they were made to understand that participation is voluntary and there was no consequence for non-participation. All information was kept confidential

\section{Results}

Of the 350 undergraduate students approached, 335 (95.7\% response rate) participated in the study. Most of the students in both schools were within the age bracket of 20-25. Most of the respondents were in the pharmacy department $(65.1 \%, \mathrm{n}=218)$. Most of the respondents in both schools were in 500 level $(49.2 \%, \mathrm{n}=49.3 \%)$. Details are shown in Table 1. Out of the seven questions, the question "Can Cervical cancer be prevented?" had the highest proportion of respondents who answered correctly, $303(90.45 \%)$. Almost half $(40.3 \%, n=135)$ of them did 
Table 1. Socio-demographic Characteristics of Students Surveyed

\begin{tabular}{lcc}
\hline Characteristics & Frequency & Percentage \\
\hline Age (Years) & 17 & \\
$<20$ & 269 & 80.29 \\
$20-25$ & 40 & 11.94 \\
$26-30$ & 6 & 1.79 \\
$31-35$ & 3 & 0.89 \\
$>36$ & & \\
Faculty & 218 & 65.07 \\
Pharmacy & 117 & 34.90 \\
Medicine & & \\
Level of Study & 116 & 34.63 \\
400 level & 165 & 49.25 \\
500 level & 54 & 16.12 \\
600 level & & \\
Marital Status & 140 & 84.48 \\
Single & 38 & 11.34 \\
Married & 6 & 4.18 \\
Engaged & &
\end{tabular}

not know that early sex debut is a risk factor for Cervical cancer (Table 2). The students of both schools had a mean knowledge score of $75.9062 \pm 20.265$. Independent T-test shows that medicine students had better knowledge than pharmacy students $[\mathrm{t}(333)=-6.167, \mathrm{p}=0.000$ (2 tailed) . The result of the study shows that the students generally had a good level of awareness of cervical cancer and its prevention (Table 3 ). The result of the study shows that majority of the students have never had sex: 183 (54.7\%) and most of them reported that they had never had an STI: 317 (94.55\%). The study shows that the students generally had a positive attitude towards cervical cancer screening and its prevention. Having attitude scores greater than or equal to the mean attitude score of $75.16 \%$ was regarded as having a positive attitude while a score lower than that was regarded as a negative attitude, the number of students that had a positive attitude was $214(63.9 \%)$ and those with negative attitude were 121 (36.1\%) (Table 4). Chi-square test showed that faculty and level of the study had a statistically significant association with the students' knowledge level (Table 5).

\section{Discussion}

The study assessed the level of knowledge, attitude, and practice of cervical cancer screening among female undergraduate students in two Nigerian universities. The students generally knew about cervical cancer, they had a positive attitude towards cervical cancer screening and prevention but a poor practice of the screening and prevention. The high response rate in this study is comparable to that in a similar study by Maharajan et al. among pharmacy undergraduate students in Malaysia [10]. This study was specifically carried out among penultimate and final year undergraduate students of Pharmacy and medicine departments since they were in clinical classes and thus expected to be have had some knowledge of oncology. A majority of the participants were within the age range of 20-25. This finding is expected since the Nigerian 6-3-3-4 system of education has 16 years as the minimum age of entry into universities. Most of the participants in the current study were single, agreeing with several similar studies carried out among undergraduate students [11-14]. Almost all the students surveyed were aware of cervical cancer and its screening. The primary source of information were health professionals unlike the study carried out among patients in an ART clinic where the media was the primary source of information about cervical cancer [9]. This may be as a result of being in clinical faculties and also still being in the university

Table 2. Students' Knowledge of Cervical Cancer

\begin{tabular}{lccc}
\hline Questions & Responses & Frequency & Percentage \\
\hline Early onset of sexual intercourse leads to cervical cancer & Correct & 200 & 59.70 \\
Having more than one sexual partner can lead to cervical cancer & Correct & 249 & 74.33 \\
Can a poor diet lead to cervical cancer? & Correct & 290 & 86.57 \\
Oral sex can lead to cervical cancer & Correct & 226 & 79.40 \\
Human papilloma virus (HPV) causes cervical cancer & Correct & 285 & 85.07 \\
Can cervical cancer be prevented & Correct & 303 & 90.45 \\
HIV-positive women are more likely to develop cervical cancer & Correct & 187 & 55.82 \\
\hline
\end{tabular}

Table 3. Students Awareness of Cervical Cancer and Its Prevention

\begin{tabular}{lccc}
\hline Questions & Responses & Frequency & Percentage \\
\hline Have you heard of cancer of the cervix & Yes & 329 & 98.2 \\
Cervical cancer is a common disease in Nigeria & Yes & 179 & 53.43 \\
Have you heard of pap smear & Yes & 272 & 81.19 \\
Have you heard of Human Papilloma Virus(HPV)? & Yes & 325 & 97.01 \\
Have you heard of HPV vaccines? & Yes & 288 & 85.97 \\
Family history of cervical cancer? & Yes & 39 & 11.64 \\
\hline
\end{tabular}


Table 4. Students Attitude towards Cervical Cancer Prevention and Screening

\begin{tabular}{|c|c|c|c|c|c|}
\hline Attitude & $\begin{array}{c}\text { Strongly Disagree } \\
\mathrm{n}(\%)\end{array}$ & $\begin{array}{c}\text { Disagree } \\
\mathrm{n}(\%)\end{array}$ & $\begin{array}{c}\text { Neutral } \\
\text { n }(\%)\end{array}$ & $\begin{array}{l}\text { Agree } \\
\text { n (\%) }\end{array}$ & $\begin{array}{c}\text { Strongly Agree } \\
\mathrm{n}(\%)\end{array}$ \\
\hline It is important for women to have regular pap tests & $7(2.09)$ & $4(1.19)$ & $17(11.64)$ & $135(40.2)$ & $150(44.78)$ \\
\hline I will be willing to screen for cervical cancer & $7(2.09)$ & $9(2.69)$ & $41(12.24)$ & $143(42.69)$ & $135(40.29)$ \\
\hline $\begin{array}{l}\text { The government should make vaccination against HPV affordable in } \\
\text { Nigeria }\end{array}$ & $9(2.69)$ & $1(0.29)$ & $5(1.49)$ & $99(29.55)$ & $121(36.12)$ \\
\hline I will get vaccinated if the vaccine is not expensive in Nigeria & $9(2.69)$ & $8(2.39)$ & $39(11.64)$ & $105(31.34)$ & $173(51.64)$ \\
\hline $\begin{array}{l}\text { The HPV vaccine should be given to adolescent girls before the onset of } \\
\text { sexual activity. }\end{array}$ & $11(3.28)$ & $13(3.88)$ & $35(10.45)$ & $106(31.64)$ & $170(50.75)$ \\
\hline
\end{tabular}

Table 5. Relationship between Students' Socio-demographic Characteristics and their Knowledge Level

\begin{tabular}{lccc}
\hline Characteristics & Correct Answers (\%) & Chi-square & P-Value \\
\hline Age (Years) & 3.65 & 7.57 & 0.109 \\
$<20$ & 80.1 & & \\
$20-25$ & 13.2 & & \\
$26-30$ & 1.85 & & $0.000^{*}$ \\
$31-35$ & 1.15 & 31.372 & $0.000^{*}$ \\
$>36$ & 46.45 & & 29.219 \\
Faculty & 53.55 & & \\
Pharmacy & & & 0.675 \\
Medicine & 24.55 & \\
Level of Study & 47.95 & 0.786 & \\
400 level & 27.5 & & \\
500 level & & & \\
600 level & 47 & & \\
Marital Status & 10.95 & & \\
Single & 5.65 & & \\
Married & & & \\
Engaged & & & \\
\hline * & & & \\
\end{tabular}

*Chi square significant at $\mathrm{p}<0.05$

environment.

Findings from the study show that the students generally had a good knowledge of cervical cancer. The students of both schools had a mean knowledge score of $75.90 \%$ which is consistent with findings from a similar study carried out among Pharmacy students in Malaysia [10]. The knowledge score in this study is much higher than the values obtained from women surveyed in Nnewi [9], Enugu [15] and Lagos [16]. This disparity is obviously due to the academic environment and medical background of the respondents surveyed in this study. The most well-known fact about cervical cancer among the students was that cervical cancer can be prevented while the least known was that an early sex debut is a risk factor for cervical cancer. Early commencement of sexual activity particularly among adolescents is associated with greater risk of cervical cancer because of vulnerability to HPV infection [17-18]. Sexual debut before 18 or 20 years is a strong determinant of cervical cancer in Nigeria where $80 \%$ adolescents are sexually active by 20 years of age and legal age of consent is 13 or 16 years in different regions. A study by Plummer et al., investigated the relationship between risk of cervical carcinoma and time since first intercourse using data on monogamous women (5,074 cases and 16,137 controls) from the International Collaboration of Epidemiological Studies of Cervical Cancer [19]. The Odd Ratio for invasive cervical carcinoma is approximately proportional to the square of time since first intercourse (exponent 1.95, 95\% CI: 1.76-2.15) up to age 45. First cervical infection with human papillomavirus (HPV) often occurs soon after first sexual intercourse, so early age at first sexual intercourse is a reasonable proxy for early age at first exposure to HPV [19].

Medicine students in both universities had better knowledge than pharmacy students, this could be because medical students extensively study cancer including practical experience compared to the pharmacy where it is more theoretical and the focus is mainly on drugs and drug therapy problems. Our participants had a high knowledge of the link between HPV and cervical cancer, greater than three-quarters of them knew that HPV was the cause of cervical cancer. This is much higher than the proportion of respondents who were knowledgeable about this link in other studies carried out in other parts of Africa [13-20]. Even though the students generally had a good attitude towards cervical cancer screening and prevention, it is still disturbing that about a third of 
the students surveyed had a poor attitude towards cervical cancer screening. This is particularly disturbing since the respondents are future health professionals expected to serve as role models and educate patients and the public at large on the importance of cervical cancer screening and prevention. More than half of the students surveyed claimed to have never had sex. This is in contrast to the findings from the study among Malaysian undergraduates where most of the respondents admitted to being sexually active. This difference may be attributed to differences in culture and values as the African culture is conservative and frowns at pre-marital sex. Thus, single female students surveyed who are sexually active may not report so. Almost three-quarters of the respondents had never consulted a gynecologist before. Almost all the students stated that they had never had a sexually transmitted infection (STI).

Previous studies among undergraduate students in health and allied courses have shown a high awareness and good Knowledge of Cervical cancer which is generally not translated into practice(Eniojukan and Ganiyu 2015; Halle-Ekane et al., 2018; Lemson and Kyi, 2018). This fact is evident in this study as only about one in seven students surveyed had ever had a pap smear. The poor practice of cervical cancer screening among respondents in this study is particularly worrisome since the students surveyed are future health professionals expected to educate the public on this practice. Surprisingly, lecturers were the least reported source of information on cervical cancer screening. This further corroborates the non-inclusion of health promotion strategies in pharmacy curricular. For pharmacists as a profession to find a role in public health, especially in developing countries, education of student pharmacists should include more direct and practical inclusion of information on basic health promotion strategies such as cervical cancer screening and vaccination in the academic curriculum and training of our pharmacy students. Lectures that only focus only on pathophysiology and treatment of cervical cancer may not be enough for these future pharmacists to fulfill their anticipated public health roles.

Some limitations to the study include the self-reporting nature of the study. Recall and social desirability bias might also have been possible. The extent to which findings from the study can be generalized to the general population is limited since the survey was carried out among students with a medical background.

In conclusion, the students generally had good awareness and knowledge of cervical cancer which was not translated into practice. There is a need to include public health principles into the curriculum of Pharmacy and Medical schools in Nigeria since they are future health advisors. Regular and periodic seminars on cervical cancer screening and prevention are also recommended.

\section{Acknowledgments}

\section{Nil}

Conflict of interest statement

The Authors declare no conflict of interest.

Funding

None

\section{References}

1. Society AC. Cancer Facts and Figures 2018. American Cancer Society. 2018.

2. Nigeria Population Council. Report of Nigeria's national population commission on the 2006 census. Population and Development Review. 2007.

3. Heath FM of. National Cancer Control Plan 2018 - 2022 [Internet]. Available from: https://www.iccp-portal.org/ system/files/plans/NCCP_Final \%5B1\%5D.pdf

4. Walboomers JMM, Jacobs M V., Manos MM, Bosch FX, Kummer JA, Shah K V., Snijders PJF, Peto J, Meijer CJLM, Muñoz N. Human papillomavirus is a necessary cause of invasive cervical cancer worldwide. J Pathol. 1999;189(1):12-9.

5. Moreno V, Bosch FX, Muñoz N, Meijer CJLM, Shah K V., Walboomers JMM, Herrero R, Franceschi S. Effect of oral contraceptives on risk of cervical cancer in women with human papillomavirus infection: The IARC multicentric case-control study. Lancet. 2002;

6. Castellsague X, Diaz M, de Sanjose S, Mu??oz N, Herrero R, Franceschi S, Peeling RW, Ashley R, Smith JS, Snijders PJF, Meijer CJLM, Bosch FX. Worldwide human papillomavirus etiology of cervical adenocarcinoma and its cofactors: Implications for screening and prevention. J Natl Cancer Inst. 2006;

7. Aggarwal P. Cervical cancer: Can it be prevented? World J Clin Oncol [Internet]. 2014;5(4):775. Available from: http:// www.wjgnet.com/2218-4333/full/v5/i4/775.htm

8. Koshiol J, Lindsay L, Pimenta JM, Poole C, Jenkins D, Smith JS. Persistent human papillomavirus infection and cervical neoplasia: A systematic review and meta-analysis. Vol. 168, American Journal of Epidemiology. 2008. p. 123-37.

9. Adibe MO, Aluh DO. Awareness, Knowledge and Attitudes Towards Cervical Cancer Amongst HIV-Positive Women Receiving Care in a Tertiary Hospital in Nigeria. J Cancer Educ. 2017;

10. Maharajan MK, Rajiah K, Sze Fang KN, Lui LY. Cervical Cancer Prevention in Malaysia: Knowledge and Attitude of Undergraduate Pharmacy Students Towards Human Papillomavirus Infection, Screening and Vaccination in Malaysia. J Cancer Educ. 2017;

11. Eniojukan Joshua, Ganiyu Kehinde IC. Vaccination among cervical cancer knowledge, awareness, screening and vaccination among female undergraduate heath professional students of niger delta university in South-South Nigeria. World J Pharm Res. 2015;(November).

12. Lemson E, Kyi KS. Knowledge , Attitude and Practices on Cervical Cancer and Its Prevention Among University. Malaysian J Nurs. 2018;9(April).

13. Halle-Ekane GE, Nembulefack DK, Orock GE, Fon PN, Tazinya AA, Tebeu PM. Knowledge of Cervical Cancer and Its Risk Factors, Attitudes and Practices towards Pap Smear Screening among Students in the University of Buea, Cameroon. J Cancer Tumor Int [Internet]. 2018;7(4):1-11. Available from: http://www.sciencedomain. org/abstract/26419

14. Akpo D, Deji P, Idiake V, Otohinoyi D, Medavarapu S. Cervical Cancer: Knowledge, Screening Practices and Vaccines 
among Female Medical Students in the Commonwealth of Dominica. Arch Med [Internet]. 2016;8(5):1-5. Available from: http://www.archivesofmedicine.com/ medicine/cervical-cancer-knowledge-screening-practicesand-vaccines-among-female-medical-students-in-thecommonwealth-of-dominica.php?aid $=17030$

15. Dim CC, Dim NR, Ezegwui HU, Ikeme AC. An unmet cancer screening need of HIV-positive women in southeastern Nigeria. Medscape J Med. 2009;11(1):19.

16. Anorlu R, Adegbesan M, Adaramewa T. Knowledge of HPV and cervical cancer among HIV-positive women in Lagos, Nigeria. Infect Agent Cancer [Internet]. 2010;5. Available from: http://www.embase.com/search/results?subaction=vi ewrecord\&from=export\&id=L70304142

17. O.O. O, O.A. A, Ogunbode OO, Ayinde OA. Awareness of cervical cancer and screening in a Nigerian female market population. Ann Afr Med. 2005;

18. Shepherd JP, Frampton GK, Harris P. Interventions for encouraging sexual behaviours intended to prevent cervical cancer. Cochrane Database of Systematic Reviews. 2011.

19. Plummer M, Peto J, Franceschi S, Cancer on behalf of the IC of ES of C. Time since first sexual intercourse and the risk of cervical cancer. Int $\mathrm{J}$ Cancer [Internet]. 2012;130(11):2638-44. Available from: http://www.ncbi. nlm.nih.gov/pmc/articles/PMC3982220/

20. Abotchie PN, Shokar NK. Cervical cancer screening among college students in Ghana knowledge and health beliefs. Int J Gynecol Cancer. 2009;

\section{(i) ()}

This work is licensed under a Creative Commons AttributionNon Commercial 4.0 International License. 